Rhode Island College

Digital Commons @ RIC

$1-1-2012$

\title{
The Impact of Timing, Selection, and Dosage of Preoperative Prophylactic Antibiotics on Preventable Surgical Site Infections
}

Cathy S. Insana

Rhode Island College

Follow this and additional works at: https://digitalcommons.ric.edu/etd

Part of the Geriatric Nursing Commons

\section{Recommended Citation}

Insana, Cathy S., "The Impact of Timing, Selection, and Dosage of Preoperative Prophylactic Antibiotics on Preventable Surgical Site Infections" (2012). Master's Theses, Dissertations, Graduate Research and Major Papers Overview. 199.

https://digitalcommons.ric.edu/etd/199

This Major Paper is brought to you for free and open access by the Master's Theses, Dissertations, Graduate Research and Major Papers at Digital Commons @ RIC. It has been accepted for inclusion in Master's Theses, Dissertations, Graduate Research and Major Papers Overview by an authorized administrator of Digital Commons @ RIC. For more information, please contact digitalcommons@ric.edu. 
THE IMPACT OF TIMING, SELECTION, AND DOSAGE OF PREOPERATIVE PROPHYLACTIC ANTIBIOTICS ON PREVENTABLE SURGICAL SITE INFECTIONS

A Major Paper Presented

By

Cathy S Insana

Approved:

Committee Chairperson

Committee Members
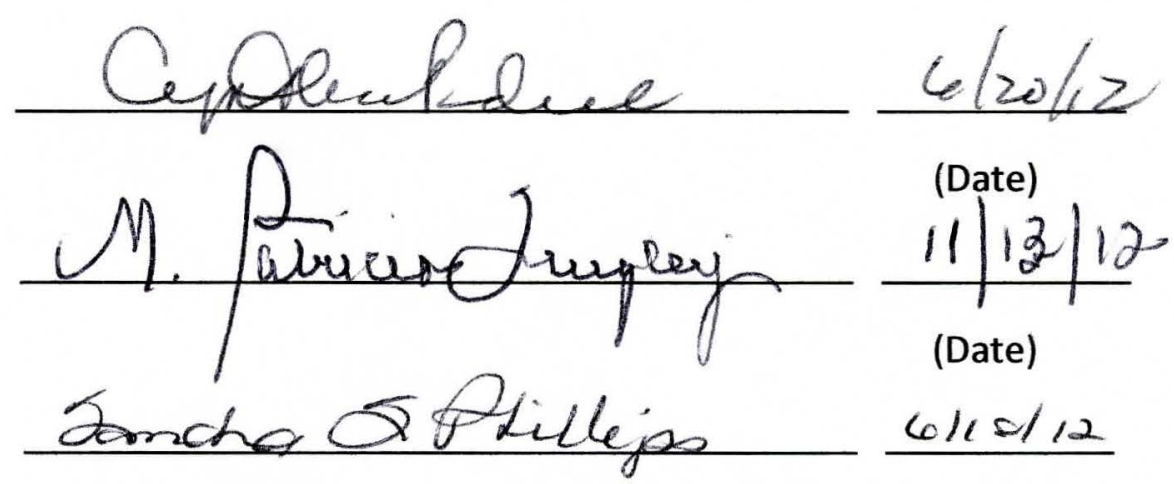

$6 / 10 / 12$

(Date)

Director of Master's Program

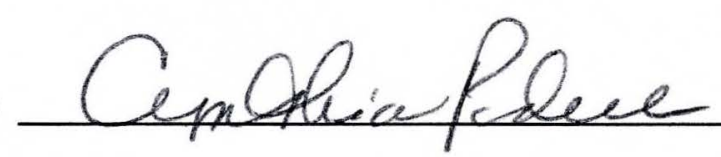

$6 / 20 / 6$

Dean, School of Nursing

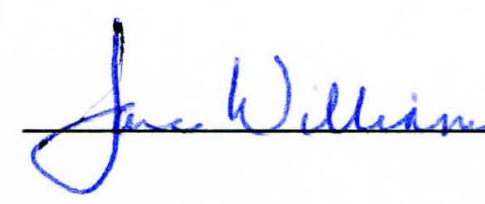

(Date)

$\frac{7 / 26 / 12}{\text { (Date) }}$ 
THE IMPACT OF TIMING, SELECTION, AND DOSAGE OF PREOPERATIVE PROPHYLACTIC ANTIBIOTICS ON PREVENTABLE SURGICAL SITE INFECTIONS

by

Cathy S. Insana

A Major Paper Submitted in Partial Fulfillment

of the Requirements for the Degree of

Master of Science in Nursing

in The School of Nursing

Rhode Island College

2012 


\begin{abstract}
Surgical site infections (SSIs) are a subset of a larger group of infections that are known as hospital acquired infections (HAIs). SSIs are a huge financial burden, costing billions of dollars in excess hospital charges every year. There is a considerable amount of evidence-based practice recommendations that can help reduce the incidence of SSIs. Research has supported the efficacy of preoperative antibiotic prophylaxis when appropriately selected and timed according to published guidelines. In addition to these measures, re-dosing of antibiotics must occur for those procedures that last more than four hours in order to continue to maintain tissue perfusion throughout the surgical procedure. The purpose of this study was to evaluate the timely administration, appropriate selection, and dosage of preoperative prophylactic antibiotics in surgical patients in one community hospital. A retrospective research design was used to obtain information on 100 randomly selected colon, hysterectomy, total hip and knee arthroplasty cases. Data were collected on those surgical procedures that occurred between October 1, 2010 and March 31,2011. During this time period, there were eight documented SSIs, three involving an organ space, and five that were superficial. In more than half of the colon and hysterectomy cases, the prophylactic antibiotic was administered less than 30 minutes before surgical incision, and in more than half of the total hip and total knee arthroplasty cases, antibiotic administration was between 30-60 minutes. All the procedures met the SCIP recommendations for timing and selection of prophylactic antibiotic. This study suggests that to ensure adequate tissue perfusion prior to surgical incision, the antibiotic should be administered in the preoperative holding unit,
\end{abstract}


immediately prior to transfer to the operating room. This would assure that the antibiotic is given 30-60 minute timeframe, thus reducing the potential for the development of a SSI. Recommendations for further research and advanced nursing practice are discussed. 


\section{Table of Contents}

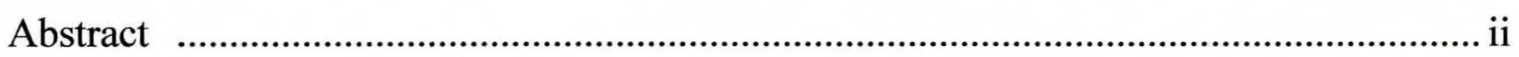

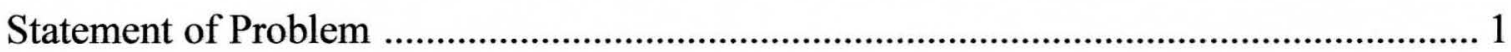

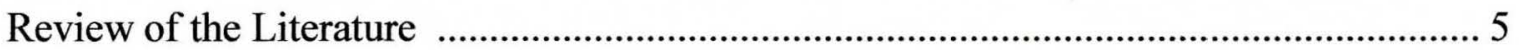

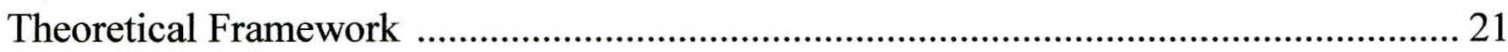

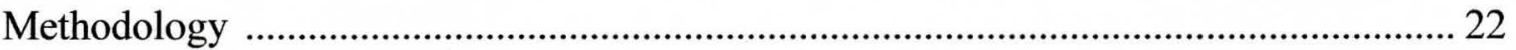

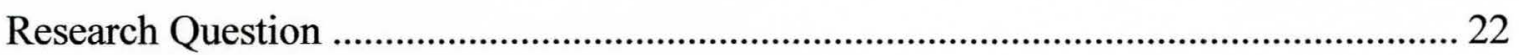

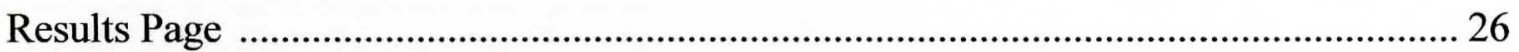

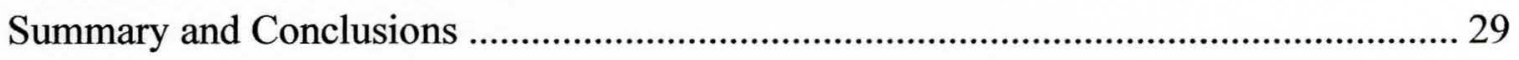

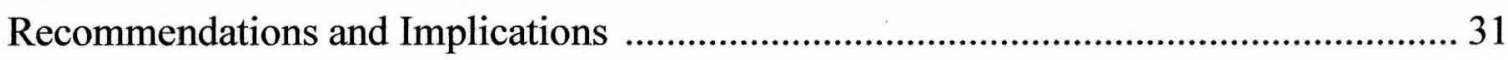

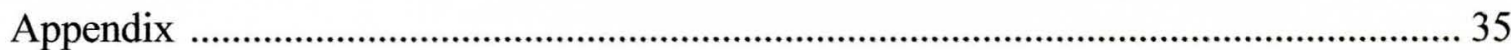

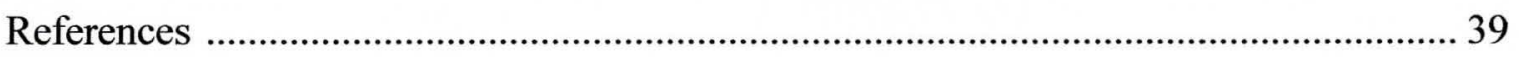




\section{Statement of the Problem}

A surgical site infection (SSI) is an unexpected event that adversely affects a patient, complicates the postoperative course, and results in a poor outcome (Fry \& Fry, 2007). SSIs are the second most common health care-associated infection (HAI) and result in increased length of hospital stay, readmissions, significant costs, and mortality. Among surgical patients, SSIs are the most common nosocomial infection, accounting for $38 \%$ of the total number (Barnett, 2007 ). According to Anderson et al. (2008), there are more than 30 million surgical procedures performed annually in the United States (US). Of those, $2-5 \%$ will develop a SSI, or one out of every 24 patients who have inpatient surgery. With shortened hospital stays and an increase in ambulatory surgical centers, the incidence of SSIs is on the rise (Anderson, Harris, \& Sexton, 2011).

Edmiston et al. (2008) reported that the probability of a patient developing a postoperative SSI is influenced by selected intrinsic, patient-related risk factors and extrinsic, procedure-related risk factors. Anderson et al. (2011) described the various patient-related risk factors that may contribute to the development of a SSI. Risks factors are separated into patient-related (preoperative), procedure-related (perioperative), and post operative categories (Table 1). These risk factors can either be modifiable or unmodifiable. An example of an unmodifiable risk factor is age; the most common and modifiable risk factor would be poorly controlled diabetes (Anderson et al.). 


\section{Table 1}

\section{Risk Factors for Surgical Site Infections and Current Recommendations to Decrease the Risk of \\ a Surgical Site Infection}

\begin{tabular}{|c|c|}
\hline Risk Factors & Recommendations \\
\hline \multicolumn{2}{|l|}{$\begin{array}{l}\text { Intrinsic or patient related } \\
\text { (Preoperative) }\end{array}$} \\
\hline Age & $\begin{array}{l}\text { No formal recommendation or relationship to increased risk of } \\
\text { SSI. } \\
\text { May be secondary to patient co-morbidities }\end{array}$ \\
\hline $\begin{array}{l}\text { Glucose control, } \\
\text { Diabetes mellitus }\end{array}$ & Control of serum blood glucose levels \\
\hline Obesity & Increased dosing of perioperative antibiotic for morbid \\
\hline Smoking Cessation & $\begin{array}{l}\text { Encourage smoking cessation within } 30 \text { days of surgical } \\
\text { procedure }\end{array}$ \\
\hline Immunosuppressive medications & No formal recommendation \\
\hline Nutrition & 2 colors \\
\hline Remote sites of infection & Identify and treat all infections before surgery \\
\hline Preoperative hospitalization & Keep preoperative stay short \\
\hline \multicolumn{2}{|l|}{$\begin{array}{l}\text { Extrinsic or procedure-related } \\
\text { (Perioperative) }\end{array}$} \\
\hline \multicolumn{2}{|l|}{ Preparation of the patient } \\
\hline Hair removal & $\begin{array}{l}\text { Do not remove unless there is hair that will interfere with the } \\
\text { surgical procedure. Hair should be clipped, not shaved and as } \\
\text { close to the time of surgery as possible }\end{array}$ \\
\hline Skin Preparation & $\begin{array}{l}\text { Wash and clean skin around the incision site. Use an approved } \\
\text { skin preparation }\end{array}$ \\
\hline Chlorhexidine nasal and oropharyngeal rinse & No formal recommendation \\
\hline Surgical scrub(surgeon's hands and forearms & $\begin{array}{l}\text { Use appropriate antiseptic agent. Perform 2-5 minute } \\
\text { preoperative skin scrub }\end{array}$ \\
\hline Incision site & Use appropriate skin antiseptic agent \\
\hline Antibiotic prophylaxis & Administer only when indicated \\
\hline Timing & $\begin{array}{l}\text { Administer within one hour of surgical incision. This time is } \\
\text { considered optimal for tissue and serum perfusion }\end{array}$ \\
\hline Choice & $\begin{array}{l}\text { Select appropriate antibiotic based on the type of surgery and } \\
\text { published guidelines }\end{array}$ \\
\hline Duration of therapy & Stop antibiotic within 24 hours after the surgical procedure \\
\hline Surgeon skills/technique & Handle tissue carefully and eradicate dead space \\
\hline Incision time & No formal recommendation \\
\hline Maintain oxygenation with supplemental $\mathrm{O} 2$ & No formal recommendation \\
\hline Maintain normothermia & $\begin{array}{l}\text { Avoid hypothermia in surgical patients. Actively warm the } \\
\text { patient to }>36^{\circ} \mathrm{C} \text { especially in colorectal surgery }\end{array}$ \\
\hline \multicolumn{2}{|l|}{ OR characteristics } \\
\hline Ventilation & Follow the American Institute of Architects recommendations \\
\hline Traffic & Minimize traffic in the Operating Room \\
\hline Environmental surfaces & $\begin{array}{l}\text { Use and EPA-approved hospital disinfectant to clean visibly } \\
\text { soiled or contaminated surfaces and equipment }\end{array}$ \\
\hline
\end{tabular}

(Anderson et al., 2011) 
The timely administration, selection, and dosage of appropriate preoperative prophylactic antibiotics is an important element in the prevention of a SSI. According to Zaidi, Tariq, and Breslin (2009), perioperative administration of antibiotics has demonstrated efficacy in reducing the risk of a SSI. The Centers for Medicare \& Medicaid Services (CMS), in collaboration with the Centers for Disease Control and Prevention (CDC), implemented the Surgical Care Improvement Project (SCIP) in the hope of decreasing morbidity and mortality that is so often associated with postoperative SSIs. Based on SCIP's current evidence based guidelines, antibiotics should be administered within 60 minutes of the surgical incision, and within 120 minutes for the administration of vancomycin and fluoroquinolones (Bratzler \& Hunt, 2006). The appropriate timing of the antibiotic should attain optimal tissue and serum drug levels and then be maintained throughout the surgical procedure (Meeks et al., 2011). The selection of the antibiotic should be based on the procedure and the published evidence-based recommendations (Anderson et al., 2008). To encourage appropropriate antibiotic prophylaxis, the CDC, CMS, and The Joint Commission (TJC) have adopted performance measures that specify the choice, timing, and duration of prophylactic antibiotics. Organizations are expected to adhere to these measures, and facility compliance is now publicly reported on a government website that can be found at http:///www.hospitalcompare.hhs.gov (Steinburg et al., 2009). Despite the high-quality evidence to support preventative guidelines and improve patient outcomes, compliance with the guidelines is suboptimal in many hospitals, usually due to patient, provider, and system level factors (Meeks et al., 2011). With the movement toward public reporting of 
quality performance measures and financial incentives such as pay-for perfomance, noncompliance with SCIP guidelines can have significant consequences for healthcare organizations (Bratzler \& Hunt, 2006).

The purpose of this study was to evaluate the timely administration, appropriate selection, and dosage of preoperative prophylactic antibiotics and the impact in the prevention of surgical site infections. 


\section{Review of the Literature}

A literature review was conducted using the following databases and websites:

Cumulative Index to Nursing and Allied Health Literature (CINAHL); Mosby's Nursing Skills; Pub Med; Up-to-Date; CDC; CMS; and TJC. Keywords used included: preoperative prophylactic antibiotics, surgical site infection, health care acquired infection, surgical wound classification, antibiotic selection, timing of antibiotic, repeat dosing of antibiotics, obesity and antibiotic prophylaxis, and the Surgical Care Improvement Project (SCIP).

\section{SSI Definition and Impact}

Historically, surgical complications were thought to be inevitable. Development of a SSI was predictable, simply a risk of the surgical business. It is now estimated that as many as $60 \%$ of SSIs are preventable, mostly related to the use of recommended evidence-based practices such as the timing, selection, and duration of preoperative prophylactic antibiotics (Meeks et al., 2011). According to Fry and Fry (2007), a SSI is an unexpected event that adversely affects a patient, complicates the postoperative course, and results in a poor outcome. Owens and Stoessel (2008) defined a SSI as an infection that has occurred within 30 days of an operative procedure or within one year if an implant has been left in place. These infections may be superficial, deep incisional or involve an organ or body space. SSIs are still a major cause of morbidity and mortality in spite of all the improvements in infection control techniques and in surgical practice (Owens \& Stoessel). 
Bucher, Warner, and Dillon (2011) completed a review of the literature that examined SSIs and prophylactic antibiotics. The purpose of their review was to highlight the progress that has been occurring with regard to the understanding of SSIs and to identify the current role of antimicrobial prophylaxis in the prevention of a SSI. The authors discussed some original studies that mainly focused on procedural risk factors for developing a SSI. For example, they refer to the CDC wound classification system that is still widely used today. This classification system is based on predicting the degree of bacterial contamination by identifying those procedures in which the likelihood of developing a SSI exists. For a SSI to occur, microbial contamination of the surgical wound must occur at the time of surgery. For many patients the comtamination occurs from endogenous flora either from the skin or exposed hollow viscus. Exogenous floral contamination of a surgical wound can transfer from operating room personnel, equipment, implants, or the medication that is administered during the procedure. There are few organisms to blame for many of the SSIs. Grampositive organisms are largely responsible for the majority of SSIs in class I wounds. In class II and III wounds, endogenous Gram-negative organisms contributed to SSIs when a hollow visus is entered. The emergence of resistant organisms that are isolated from the surgical wound is becoming a major concern with regards to the development of a SSI. In particular methicillin-resistant staph aureus (MRSA) and the percentage of infections attributed to MRSA has dramatically increased. It has been found that MRSA accounts for $23 \%$ of all Gram-positive isolates and $20 \%$ of all SSI isolates. Also patients with MRSA attributed SSIs had longer hospital stays, increased cost of 
care, and higher mortality rates. The authors go on to say that currently the CDC does not recommend routine antibiotic prophylaxis to cover MRSA except in certain clinical circumstances. It depends on the type and location of the MRSA. Antimicrobial prophylaxis is an attempt to reduce the risk of a SSI by timing the administration of an antibiotic to match the potential intra-operative wound contamination. Antibiotic prophylaxis is recommended for all procedures with a high SSI risk (class II and III), or any procedure which poses a high risk for the development of a SSI. The use of an antimicrobial prophylaxis is not recommended by the $\mathrm{CDC}$ if there are no additional risk factors. There are three principles with regards to the use antimicrobial prophylaxis: the agent must cover the pathogens specific to the planned surgical procedure, administration of an antimicrobial to establish bactericidal tissue levels must occur prior to incision, and continued administration of an antimicrobial should last no longer than 24-48 hours after the procedure has been completed. The timing of antimicrobial prophylaxis is critical to its efficacy. In procedures where the administration of the antibiotic occurred within 2 hours of incision, the risk of a SSI was greatly reduced compared with an antibiotic administered earlier than 2 hours. There is no evidence to support the continuation of an antimicrobial beyond 24 hours after the procedure. The continuation of an antimicrobial for longer durations may actually increase the risk of developing a resistant organism. The authors concluded that patients, surgeons, and hospitals have a vested interest in preventing SSIs and that several decades of data have demonstrated the ability of antibiotic prophylaxis to significantly reduce the risk of an SSI. 
There is considerable cost associated with the development of a SSI. The expense varies widely depending on the severity of the infection and treatment course. Barnett (2007) reported that each SSI causes an additional 7-10 postoperative hospital days. Depending on the type of infection and infecting pathogen, the cost of treating a SSI ranges from $\$ 3,000-\$ 29,000$ and adds up to $\$ 10$ billion annually (Barnett); the cost when due to a resistant organism is likely even higher (Anderson et al., 2011). Most estimates are based on inpatient costs and do not account for the additional costs of rehospitalization, post-discharge outpatient expenses, and any long term disabilities (Barnett, 2007). SSIs pose a substantial clinical burden (Owens \& Stoessel, 2008).

Kirkland, Briggs, Trivette, Wilkinson, and Sexton (1999) studied 215 matched pairs of patients with a SSI and those without. The relative risk for death associated with a SSI was $2.2 \%$, while the relative risk for readmission and ICU treatment were 5.5\%. Patients who developed a SSI required longer hospitalization: the mean duration was 11 days for the infected patient versus six days for the uninfected patient. The mean extra hospital duration was 6.5 days, and in a SSI involving organs or body space, there was even a longer hospital duration and increased costs compared with a SSI that only involved the incision or was superficial in nature.

Morbidity and mortality is associated with SSIs. Patients that develop a SSI are up to $60 \%$ more likely to spend time in the Intensive Care Unit (ICU), where care is costly for both the patient and hospital (Barnett, 2007). The patient with a SSI is five times more likely to be readmitted to the hospital (Fry \& Fry, 2007), and 77\% of deaths among patients with a SSI are directly attributable to the SSI. Potentially 
preventable complications are estimated to add $9.4 \%-9.7 \%$ to hospital inpatient costs (Fuller, McCullough, Bao, \& Averill, 2009).

\section{Evidence Based Guidelines and Initiatives for Prevention of SSIs}

CMS created the Surgical Infection Prevention Collaborative (SIP) (Anderson et al., 2008) in 2002 to identify performance measures for quality improvement related to antibiotic prophylaxis. SIP recommendations include prophylactic antibiotic within one hour of surgical incision (two hours for vancomycin and fluoroquinolones), and the antibiotic selected must be on the published guidelines and discontinued within 24 hours after surgery. The SIP collaborative focused on seven procedures: abdominal hysterectomy; vaginal hysterectomy; hip arthoplasty; knee arthroplasty; cardiac;vascular; and colorectal. Those hospitals that implemented and improved compliance with SIP performance measures saw their SSI rates go down.

The Surgical Care Improvement Project (SCIP), an extension of SIP, was started in 2005 in an attempt to significantly reduce the incidence of surgical complications through collaborative efforts. SCIP continues to assess the performance measures of SIP and also provides evidence based information about the prevention of complications. SCIP became a national quality partnership that was created in collaboration with CMS and the $\mathrm{CDC}$, along with representatives of the Veterans Administration (VA), the American College of Surgeons (ACS), the American Society of Anesthesiologist (ASA), the Agency for Healthcare Research and Quality (AHRQ), the American Hospital Association (AHA), and The Institute for Healthcare Improvement (IHI) (Bratzler \& Hunt, 2006). This partnership focused on reducing the incidence and cost of 
complications in surgery. Recommendations included the proper use of antibiotics as defined by the SCIP measures (Appendix A). This project has led to a reduction in surgical complications as a result of healthcare professionals' attitudes toward surgery (Clancy, 2008). CMS estimates that compliance with the SCIP measures will help prevent up to 13,027 perioperative deaths and 271,055 surgical complications annually for Medicare patients alone (Bratzler \& Hunt, 2006).

On the federal government level, healthcare organizations must meet SCIP requirements in order to be reimbursed for services rendered. Anderson et al. (2008) described the creation of the Deficit Reduction Act in 2005 that requires acute care hospitals that are paid by Medicare to submit quality measure information to CMS as a requirement for reimbursement. This requirement allows CMS to adjust payments downward for those patients that develop a HAI. CMS now requires inclusion of prophylactic antibiotics within one hour of surgery and antibiotics to be discontinued within 24 hours after surgery as a quality measure for payment.

\section{Research Regarding Evidence Based Strategies}

In 1999, the Infection Control Advisory Committee that is part of the CDC published guidelines that outlined the principles of prophylactic antibiotic administration for surgical practice. The guidelines include: identification of procedures that would benefit from prophylactic antibiotics; drug of choice for selected procedures; recommended timing of the antibiotics; duration of use; and discontinuing antibiotics. Another tool that perioperative practitioners can use that addresses data collection and analysis related to SSI prevention is the Specifications Manual for National Hospital Inpatient Quality 
Measures (Appendix B). These guidelines represents a collaborative effort between CMS and TJC, and provide algorithms that outline prophylactic antibiotic administration as well as the correct antibiotic for particular procedures (Wanzer, Goeckner, and Hicks , 2011).

Accurate and timely administration of antibiotics is a critical element in perioperative care (Wanzer et al., 2011), and the most important factors in the prevention of SSIs are meticulous aseptic technique and the timely administration of selected preoperative antibiotics (Anderson et al., 2011). The goal of antibiotic prophylaxis is to prevent a SSI by reducing the microorganisms at the surgical site during the operative procedure. The efficacy of antibiotic prophylaxis for reducing a SSI has been clearly established (Anderson et al.). Patients who receive prophylactic antibiotics within one hour to two hours before surgical incision have lower rates of SSI than those patients who receive antibiotics closer to the time of incision. However, errors in selection or dose of prophylactic antibiotics are common. Among 34,133 patients undergoing surgery in centers around the US, an antibiotic administered within one hour of the incision occurred in only $56 \%$ of patients (Anderson et al.)

\section{Timing, Selection and Dosage}

Classen et al. (1992) conducted a prospective observational study of 2,847 patients that underwent elective clean or clean contaminated procedures at a large community hospital. Of the 1708 patients who received the prophylactic antibiotic preoperatively, or two hours before surgical incision, only 10 developed a SSI. In 282 patients that received the antibiotic perioperatively, or three hours after surgical incision, only four 
developed a SSI $(\mathrm{p}=.12)$ compared with the perioperatively treated group. Of 488 patients who received an antibiotic postoperatively, more than three hours but less than 24 hours after surgical incision, 16 patients developed a wound infection $(p<.0001)$. Lastly, patients that had the antibiotic administered early, 2-24 hours before surgery, 14 developed an infection $(\mathrm{p}<.0001)$. The investigators noted that this analysis confirmed their suspicions that the administration of an antibiotic in the perioperative period was associated with a lower risk of the patient developing a SSI. They concluded that the administration of prophylactic antibiotics is significantly varied in institutions, but administration of antibiotics two hours prior to surgical incison will reduce the probability of developing a SSI.

Zanetti, Giardina, \& Platt (2001) conducted a retrospective study that compared the risk of SSI in 1,548 patients having cardiac surgery that lasted more than four hours. The researchers also examined the possible value of intraoperative redosing for extended surgical procedures. These patients received cefazolin preoperatively and then $30 \%$ received a repeat dose intraoperatively. The overall risk of a SSI was similar among the patients with $(n=43[9.4 \%]$ of 459$)$ and without $(n=101[9.3 \%]$ of 1089$)$ of intraoperative dosing. Redosing was beneficial in those procedures that lasted greater than 4 hours. Infections occurred in $7.7 \%(n=14)$ of patients with redosing and in $16 \%$ $(n=32)$ of patients without. Intraoperative redosing of cefazolin was associated with a $16 \%$ reduction in the overall risk of developing a SSI in cardiac surgery and included those procedures that lasted greater than 240 minutes. 
Edmiston, Kelly, Larson, Andris, \& Hennen (2004) conducted a study with the bariatric patient population to assess serum and tissue levels resulting from administration of a 2 gram (gm) dose of cefazolin. The primary purpose of the study was to determine if perioperative antibiotic prophylaxis provided therapeutic and effective drug concentrations in tissue prior to the surgical incision, intraoperatively, and after skin closure. Patients undergoing Roux-en-Y gastric bypass for morbid obesity were treated prophylactically with a 2 gm dose of cefazolin preoperatively. They were then followed by a second dose of antibiotics at three hours. There were 38 patients and each was assigned to one of three body mass index (BMI) groups: A group $(n=17)$ with a BMI 40-49; B group $(\mathrm{n}=11)$ with a BMI 50-59; and group C $(\mathrm{n}=10)$ with a BMI greater than 60 . There were multiple, timed serum levels obtained at baseline, during surgical incision, and at 15, 30, and 60 minutes prior to the administration of the second dose of prophylactic antibiotic. Tissue that included skin, subcutaneous fat, and omentum was also collected and analyzed by microbiological assay to determine the cefazolin concentrations. The analysis revealed that over $90 \%$ of the serum samples had therapeutic levels that covered $53.8 \%$ of gram positive and $76.6 \%$ of gram negative surgical pathogens. Therapeutic tissue levels were achieved in only $48.1 \%, 28.6 \%$, and $10.2 \%$ of groups A, B, and C. The investigators concluded that less than $29 \%$ of the tissue samples had enough of a cefazolin concentration to inhibit either staphylococcus aureus or staphylococcus epidermidis in the surgical wound. The findings of this study suggested that a $2 \mathrm{gm}$ dose of an antibiotic prophylaxis is suboptimal in those patients with a BMI greater than 40 . The investigators suggested that surgical practitioners 
consider increasing the prophylactic dose of antibiotic in elective surgery for those patients with a high BMI.

Weber et al. (2008) conducted a prospective observational cohort study that examined the incidence of SSI and the timing of antibiotic prophylaxis in 3,836 consecutive surgical procedures. The purpose of this study was to obtain accurate information on the optimal timeframe for administration of surgical prophylactic antibiotics. The researchers reported that although perioperative antimicrobial prophylaxis is a well known approach for reducing the risk of a SSI, the optimal timing for administration of an antibiotic has not been precisely determined. Consecutive surgeries conducted between January 1, 2000 and December 31, 2001 that were performed in the Visceral, Vascular, and Tramatology Divisions of the General Surgery Department at Basel University Hospital in Basel, Switzerland were included in this study. Excluded procedures included those that: did not have an incision; had a hospital stay of less than 24 hours; had a wound classification of dirty-infected; were procedures in which antibiotics were administered for more than 24 hours after surgical incision; did not comply with the hospital guidelines for administration of prophylactic antibiotic within 2 hours before skin incision. Surgical wounds and any resulting infection were assessed using CDC standards. A total of 82 variables were examined, including but not limited to age, sex, underlying disease, additional diagnoses, American Society of Anesthesiologists (ASA) score, type of surgery, surgical team members, wound class, duration of surgery, length of hospital stay, and intensive care before and after the surgery. The methods used for postdischarge monitoring of the patient included: 30 days for non-implant and one 
year for implant surgery. Any case that showed evidence of a SSI was validated by a board certified infectious disease specialist. Antimicrobial prophylaxis was administered by the anesthesia team and included a single dose of intravenous (IV) infusion of $1.5 \mathrm{gm}$ of cefuroxime in 20 milliters $(\mathrm{ml})$ of sodiun chloride over 2-5 minutes. This antibiotic was combined with metronidazole (500 milligrams (mg), IV, over 5 minutes) in colorectal patients; for patients with renal failure, the dosage was adjusted based on creatinine clearance. Colorectal patients received no intralumimal antibiotics but did complete a bowel preparation. The data was divided into time intervals of 30-60 minutes and 0-29 minutes before skin incision. Overall the SSI rate was $4.7 \%(\mathrm{n}=3836)$. In $49 \%$ of all the procedures, an antimicrobial prophylaxis was administered within the half an hour prior to the start of the procedure. Multivariable logistic regression analyses was able to demonstrate an increase in the odds of a SSI when antimicrobial prophylaxis was administered less than 30 minutes $(\mathrm{p}<.001)$ and $60-120$ minutes $(\mathrm{p}=.035)$ as compared to $30-59$ minutes before incision is made. The researchers concluded that the risk of developing a SSI is reduced when cefuroxime is used as a prophylactic antibiotic and given 30-59 minutes before the surgical incision is made.

Nelson, Glenny, and Song (2008) conducted a systematic review published by The Cochrane Colloborative. They examined randomized controlled trials (RCTs) published between January 1980 and December 2007 to assess the effectiveness of antimicrobial prophylaxis in the prevention of a surgical wound infection (SWI) in elective and emergency colorectal surgery. The goal of this systematic review was to look at the principles of antibiotic administration. The investigators looked at the timing of 
antibiotic administration, duration, route, and the bacterial coverage needed in an antibiotic for the prevention of a SWI in elective colorectal surgery. This review included 182 RCTs $(30,880$ patients) and a total of 50 different antibiotics, with 17 that included cephalosporins, thought to be the antibiotic that contributes to Clostridium difficile colitis (C-diff) infection. This type of procedure was selected due to the fact that the abdominal wound has the greatest risk of infection, most commonly from colorectal bacteria contamination. Ten trials (813 patients) were published between 1980 and 1996 that compared administration of some type of prophylactic antibiotic with that of no treatment as the control/placebo. The overall result of these trials showed that their was "significant benefit" $(p<.00001)$ in favor of antibiotic prophylaxis with a variety of antibiotics. Twenty-five trials $(\mathrm{n}=3589)$ published between 1984 and 2000 looked at short term versus long term use of an antimicrobial either alone or in combination with another antimicrobial agent. These trials were studied in several different formats and the researchers concluded that there was no advantage with longer dosing of an antimicrobial $(p=0.51)$. It was recommended that for those antibiotics with a shorter half life, a second dose should be given for longer surgical procedures. Eleven trials (1269 patients) studied antimicrobial prophyaxis treatment with additional aerobic coverage versus the same antimicrobial treatment with no additional aerobic coverage. These trials demonstrated that if a patient received an antibiotic that covered anaerobic bacteria, and an antibiotic that covers aerobic bacteria is added, there is a considerable reduction in the incidence of a SWI, though not significant $(\mathrm{p}=.17)$. Fifteen trials (2394 patients) that were published between 1980 and 1992 examined antimicrobial prophylaxis treatment 
with no other aerobic coverage compared to the same treatment without extra anaerobic coverage. These trials demonstrated that the addition of an antibiotic with anaerobic coverage to an antibiotic with aerobic coverage resulted in a reduction in the development of a SWI $(p=.008)$. There was just one RCT $(n=72))$ that compared the effectiveness of kanamycin and metronidazole when given by different routes of administration. In this study there was no significant difference in SWI rates. Thirteen reports ( $\mathrm{N}=2362$ ) examined a combination of oral and intravenous (IV) antimicrobial prophylaxis compared to only IV antimicrobials. The results indicated that combining both oral and IV antibiotics was beneficial compared to IV alone with regards to antibiotic prophylaxis $(\mathrm{p}<.0001)$. Three studies $(\mathrm{N}=283)$ studied antibiotic prophylaxis that was given both orally and IV and compared to the oral route only.

These trials demonstrated a considerable benefit for the combination of oral and IV dosed antibiotics compared to only oral doses of prophylactic antibiotics $(p=.02)$. Twenty-eight trials $(\mathrm{N}=3077)$ studied administration of various types of prophylactic antibiotic. The analysis compared any type of antibiotic with those antibiotics regarded as the "gold standard" in antimicrobial treatment: oral neomycin, erythromycin, IV cefoxitin or cefotetan, and IV doxycycline. The purpose of this analysis was to detect statistical significance from the existing data with regard to those antibiotics deemed as gold standard antibiotics. One trial compared IV ceftriaxone and metronidazole to oral neomycin and erthromycin with substantial benefit however, other ceftriaxone studies did not show a benefit in the prevention of a SWI when this antibiotic was compared to other IV choices. There was an additional trial that resulted in considerable benefit with both 
oral and IV doses of two gold standard drugs, IV cefoxitin and oral neomycin/erythromycin. These drugs were found to be more effective in combination versus using each alone however, the results of this trial were inconclusive.

From this meta-analysis, Nelson et al. concluded that antibiotic prophylaxis is essential for patients having colorectal surgery. The potential exposure of the operative field to comtaminated colonic contents is enough to warrant the use of prophylactic antibiotics. An IV antibiotic must be administered before surgery with the best time being one hour before surgical incision however, the investigators acknowledge that determination of the optimal timing of prophylactic antibiotics is currently lacking evidence. The analysis found no need for re-dosing postoperatively, and the antibiotics selected for prophylaxis must cover both aerobic and anaerobic bacteria.

In what was probably the largest multicentered prospective study related to this topic, Steinburg et al. (2009) examined the relationship between antibiotic timing and SSI risk. The Trial to Reduce Antimicrobial Prophylaxis Errors (TRAPE) Study Group aimed to determine the optimal timing for surgical antibiotic prophylaxis. This group believed that national antibiotic guidelines should be well supported by evidence and this could only be obtained from large data sets. Twenty nine hospitals prospectively obtained information on antibiotic prophylaxis from 4,472 randomly selected cardiac, hip arthroplasty, knee arthroplasty, and hysterectomy cases. Only cephalosporins or other antibiotics that were designated by SCIP guidelines were administered. In the study, 3,405 patients received antibiotic within 60 minutes of incision; 575 patients received cephalosporins and vancomycin; 218 received vancomycin only; 240 received 
fluorquinolones with or without other agents; and 34 had no documented antiobiotic prophylaxis. The antibiotic selection met SCIP indicators in $90 \%$ of the cases. All TRAPE participating hospitals then measured antibiotic prophylaxis performance in 100 randomly selected surgical cases in two, six month periods from June to November 2003 (baseline) and February to July 2005 (re-measurement). The authors found that 113 SSIs occurred in 109 patients (four patients with multiple infections), and that the risk of an SSI increased as the interval of time between antibiotic infusion and the surgical incision increased. In 1,062 cases, the surgical procedure lasted greater than four hours, and only $21 \%$ of the patients received intraoperative redosing. The data supported that redosing appears to reduce the incidence of SSI risk for those procedures lasting more than four hours, but only when the preoperative dose was given correctly. This study was of major importance as it found a consistent relationship between antibiotic prophylaxis timing and infection risk. There was a lower risk when cephalosporins and other antibiotics with short infusion times were given 30 minutes prior to surgical incision $(p=0.04)$. The authors noted that compliance with SCIP measures ultimately reduced the risk of infection. However, they stated that organizations should improve compliance with intraoperative repeat dosing during long surgeries as this is a major cause of antibiotic prophylaxis errors. Anderson (2011) reported that antibiotic therapy should be admininistered within 60 minutes prior to the surgical procedure to ensure adequate drug tissue levels at the time of surgical incision or 120 minutes if vancomycin or a fluoroquinolone is being used. 
Meeks et al. (2011) conducted a retrospective chart review in adult patients undergoing elective and emergent lapartomies for colorectal procedures abdominal hysterectomies, and abdominal vascular procedures. The researchers studied compliance with SCIP measures and prevention of SSIs. Patients were selected using a randomized chart audit, and emergent cases were included due to the increased risk of developing an SSI. The study was conducted during two six month periods, July and December 2006 and July and December 2007. During the timeframe of the study, no specific interventions were initiated within the organizations to improve compliance. There were 517 patients included in the study, including 316 abdominal hysterectomies, 189 colorectal and 14 abdominal, vascular cases. Overall compliance with all three antibiotic guidelines only occurred in $62 \%(274 / 442)$ of the cases. While the researchers were able to report improvement in compliance with SCIP, they stated that there is room for improvement. They reported that the study provided information that can be used to develop intervention to help improve compliance (Meeks et al.).

In summary, the research supports the appropriate timing and selection of preoperative prophylactic antibiotics in preventable surgical site infections. However, the evidence is lacking in regard to repeat dosing during surgical procedures lasting greater than four hours. In light of CMS and TJC's "pay for perfomance" initiatives and public reporting, healthcare organizations need to explore the relationship between redosing and the risk of developing a SSI. Research is key to prevention.

Next, the theoretical framework that guided this study will be presented. 


\section{Theoretical Framework}

\section{The Perioperative Patient Focused Model}

The theoretical framework selected for this research study is the Perioperative Patient Focused Model (Rothrock \& Smith, 2000). This conceptual framework is used in perioperative nursing practice and places the patient and his/her designated support person(s) at the core of the model. Concentric circles that extend beyond the patient and their support person(s) represent perioperative nursing domains and elements. This model is composed of four domains including patient safety, physiologic responses, and behavioral responses, and the healthcare system in which perioperative care is provided (Appendix C). The choice of this patient focused model is fitting for this research project as it centers on the patient and positive outcomes, which is the true focus of perioperative nursing. The development of a surgical site infection impacts the patient's physical and behavioral well being, compromises patient safety, and can have major financial impact on the healthcare facility. A common complication of surgery, SSI is known to increase morbidity and mortality, length of hospital stays, and health care cost (Allen, 2009). This nurse-driven model utilizes the perioperative nurse's unique knowledge base to care for all types of patients and procedures. Using the nursing process, the perioperative nurse should perform an individual patient assessment, determine the patient's SSI risk, formulate a nursing diagnosis, and select those interventions that will aid in prevention of an SSI ("Standards of Perioperative Nursing," 2011).

In the next section, the method used in this study will be presented. 


\section{Methodology}

\section{Purpose/Specific Aims}

The purpose of this study was to evaluate the timely administration, appropriate selection, and dosage of preoperative prophylactic antibiotics, and the impact in the prevention of surgical site infections.

\section{Research Question}

The research question was: What impact did the timing and selection of prophylactic antibiotics have on preventable surgical site infections.

\section{Design}

This research study utilized a retrospective design with chart audits ( Polit \& Beck, 2008).

\section{Site and Sample}

This study was conducted at a community hospital in Rhode Island. The sample included patients who underwent surgery at the study site who met the inclusion criteria: adults undergoing elective and emergent colon, hysterectomy, hip, and knee arthroplasty. This subset was selected because these procedures have specific recommendations from SCIP regarding preoperative antibiotic prophylaxis. Exclusion criteria included: less than 18 years of age; a hospital length of stay greater than 120 days; underwent any procedure performed entirely by a laparoscope; a documented infection prior to the surgical procedure; any diagnosis suggestive of a preoperative infectious disease; receiving antibiotics more than 24 hours prior to surgery (except colon surgery). 


\section{Procedure}

Permission to conduct this study was obtained from the Chief Nursing Officer, Director of Surgical Services, and immediate supervisors. Institutional Review Board (IRB) approval was obtained from Rhode Island College and the community hospital's IRB. After approval, data were collected on surgical cases that occurred between October 1, 2010 and March 31, 2011. The electronic medical record for those patients with elective and emergent colon, hysterectomy, hip and knee arthroplasty within the designated timeframe were reviewed using data collection sheets supplied by the Quality Improvement (QI), Infection Prevention and Control (IPC) departments, and Cerner®) electronic documentation software at the community hospital. The QI department uses the Thompson-Reuters Care Discovery Data Measure software to track those surgical procedures that are part of the SCIP initiative. The IPC department at the time of this study used a Microsoft Excel® spreadsheet for tracking all reported SSIs.

A target sample of 100 was desired. Based on the surgical volume, this researcher collected data on every 3rd surgical procedure that met the inclusion criteria. All records were first reviewed for inclusion criteria and if not met, were excluded. Data collected were de-identified and stored in a locked file accessible only to the researcher. If any data was missing, the patient record was excluded from the study and the data collection tool was destroyed.

\section{Measurement}

After determining eligibility, a data collection tool developed by this researcher was used to collect relevant data (Appendix D). Using the subjects' medical record number 
as the identifier, demographic information was obtained that included sex, age, weight, BMI (body mass index), male or female gender, and any co-morbidities. This researcher then utilized SCIP data obtained from QI to collect information from the subjects' medical record that included the type of surgery/procedure, including surgical start and stop times. Risk factors for infection were evaluated including: diabetes/type; smoking history; previous infections; infectious disease present ( e.g. MRSA); recent hospitalizations; antibiotics administered in the past 24 hours; and oral prophylaxis for colon surgery (if applicable). Data related to the timing of prophylactic antibiotics, the name/type of antibiotic administered, repeat dosing for surgical procedures greater than four hours, and if the patient received preoperative antibiotic prophylaxis were collected. Any re-dosing of antibiotic during the surgical procedure was included in the data collection only if the patient had received a preoperative prophylactic antibiotic.

To identify SSI infections from the sample, the IPC provided a list of reported SSIs during the timeframe of this study. Any data relevant to the infection was also documented in this researcher's data collection tool. The data collected from both the QI and IPC departments were entered into a Microsoft Excel ${ }^{\circledR}$ database that was created and maintained by the researcher. There is no computer software in the hospital that enables the QI and IPC departments to correlate their data with respect to SSIs and antibiotic administration or timing. 


\section{Timeframe}

Data collection for this study was completed over an 6 month time period.

\section{Human Subjects Considerations}

This was a retrospective design and thus patient consent was not needed. Data collected included the medical record number but only for selection of the correct medical record. Once the data collection record was completed for a subject, the medical record number was removed. Anonymity and confidentiality was maintained throughout the study. Data was collected by the researcher and stored in a locked file that only the researcher and faculty advisor had access to. All data collected was destroyed immediately upon completion of the study.

\section{Data Analysis}

Data gathered were entered into an Microsoft Excel ${ }^{\circledR}$ spreadsheet for the purposes of organizing patient data. The exact timing of prophylactic antibiotic administration before incision and the start of the surgical procedure was calculated in minutes and entered into a frequency distribution table. The mean, median, and mode of all the selected surgical procedures were determined along with IPC data to correlate the incidence of a documented SSI within the timeframe of this study. 


\section{Results}

Overall, 100 medical records were reviewed, with $82(82 \%)$ comprising the sample, and $18(18 \%)$ records excluded due to incomplete records. The sample included 54 (54\%) females and $28(28 \%)$ males, and the mean age was 65.42 years with a range of 40-91 years.

The sample identified by procedure included: 15 colorectal cases $(23.07 \%) ; 12$ hysterectomy cases (18.46\%), 25 total knee arthroplasty cases (38.46\%); and 30 total hip arthroplasty cases $(46.15 \%)$.

Body mass index (BMI) was calculated to determine the need for weight-adjusted dosing in a subset of subjects, those with a BMI greater than 30. The mean BMI for all subjects was 25.8. Twenty-two subjects had a BMI of greater than 30 , indicating obesity, with a mean BMI of 36.51. No weight adjusted dosing was detected for any of those subjects with a BMI greater than 30. Prophylactic antibiotic dose was administered 0-29 minutes before surgical incision in 27 cases (32.9\%). In another 54 cases (65\%), the prophylactic antibiotic was given 30-60 minutes before surgical incision. The mean time of antibiotic administration was 31.23 minutes. There were two cases in which the procedure lasted greater than four hours, with no re-dosing in either case. In more than half of the colon (53\%) and hysterectomy (58\%) procedures, the prophylactic antibiotic was administered in a 0-29 minute timeframe, whereas in the total hip (72\%) and total knee $(60 \%)$ arthroplasty cases, the antibiotic was given within a 30-60 minute timeframe. Compliance with the choice of antibiotic did meet SCIP recommendations in all procedures $(100 \%)$. There was no re-dosing $(0 \%)$ for colon and hysterectomy procedures 
that lasted greater than 4 hours, and no $(0 \%)$ procedure adjusted the dose of antibiotic based on weight or BMI. Compliance with SCIP selection of antibiotics by type of procedure as well as the timing, and administration of antibiotics are illustrated in Table 3 .

Table 3

Comparison of Antibiotic Compliance with SCIP Guidelines by Case

\begin{tabular}{|c|c|c|c|c|}
\hline $\mathrm{N}=82$ & $\begin{array}{c}\text { Colorectal } \\
\mathrm{N}=15\end{array}$ & $\begin{array}{c}\text { Hysterectomy } \\
\mathrm{N}=12\end{array}$ & $\begin{array}{c}\text { Total Hip } \\
\mathrm{N}=25\end{array}$ & $\begin{array}{c}\text { Total Knee } \\
\mathrm{N}=30\end{array}$ \\
\hline \multirow{2}{*}{$\begin{array}{l}\text { Compliance with } \\
\text { antibiotic timing } \\
\text { prior to incision }\end{array}$} & $\begin{array}{c}0-29 \text { minutes } \\
\mathrm{N}=8(53 \%)\end{array}$ & $\begin{array}{c}0-29 \text { minutes } \\
\mathrm{N}=7(58 \%)\end{array}$ & $\begin{array}{l}0-29 \text { minutes } \\
\mathrm{N}=7(28 \%)\end{array}$ & $\begin{array}{l}0-29 \text { minutes } \\
\mathrm{N}=12(40 \%)\end{array}$ \\
\hline & $\begin{array}{c}30-60 \text { minutes } \\
\mathrm{N}=7(46 \%)\end{array}$ & $\begin{array}{c}\text { 30-60 minutes } \\
\mathrm{N}=5(42 \%)\end{array}$ & $\begin{array}{c}30-60 \text { minutes } \\
\mathrm{N}=18(72 \%)\end{array}$ & $\begin{array}{c}30-60 \text { minutes } \\
\mathrm{N}=18(60 \%)\end{array}$ \\
\hline $\begin{array}{l}\text { Compliance with } \\
\text { antibiotic } \\
\text { selection }\end{array}$ & $\mathrm{N}=15(100 \%)$ & $\mathrm{N}=12(100 \%)$ & $\begin{array}{l}\mathrm{N}=25(100 \%) \\
1 \text { case received } \\
\text { Vancomycin* }\end{array}$ & $\begin{array}{c}\mathrm{N}=30(100 \%) \\
1 \text { case received } \\
\text { Clindamycin* } \\
\end{array}$ \\
\hline $\begin{array}{l}\text { Compliance with } \\
\text { re-dosing for } \\
\text { procedures } \square 4^{\circ}\end{array}$ & $\begin{array}{l}\mathrm{N}=1 \\
\text { Length of } \\
\text { procedure }=4.23 \\
\text { hours } \\
\text { No re-dosing } \\
\qquad(0 \%)\end{array}$ & $\begin{array}{l}\mathrm{N}=1 \\
\text { Length of } \\
\text { procedure }=4.16 \\
\text { hours } \\
\text { No re-dosing } \\
\qquad(0 \%)\end{array}$ & $\begin{array}{c}\text { No procedures } \\
\square 4^{\circ}\end{array}$ & $\begin{array}{c}\text { No procedures } \\
\square 4^{\circ}\end{array}$ \\
\hline $\begin{array}{l}\text { Weight adjusted } \\
\text { dosing for } \mathrm{BMI} \geq \\
30\end{array}$ & $\begin{array}{c}\text { No (all cases) } \\
(0 \%)\end{array}$ & $\begin{array}{c}\text { No (all cases) } \\
(0 \%)\end{array}$ & $\begin{array}{c}\text { No (all cases) } \\
(0 \%)\end{array}$ & $\begin{array}{c}\text { No (all cases) } \\
(0 \%)\end{array}$ \\
\hline
\end{tabular}

* Vancomycin and Clindamycin alternative antibiotic for patients with PCN allergy 
Table 5 illustrates the sample participants who were identified as having a SSI. Overall, this table demonstrates that the selection of antibiotic for those procedures resulting in a SSI did meet the SCIP recommendations. The timing of the antibiotic in those cases where the administration of the antibiotic is less than 30 minutes prior to incision does meet SCIP recommendations, however this is not considered optimal timing for adequate tissue perfusion. During this time period, there were eight documented SSIs, three involving an organ space and five that were superficial.

Table 5

Surgical Site Infections October 1, 2010-March 31, 2011

\begin{tabular}{|c|c|c|c|c|c|}
\hline & Procedure & $\begin{array}{l}\text { Infection } \\
\text { Type }\end{array}$ & Prophylactic Antibiotic & $\begin{array}{l}\text { Administration of Antibiotics } \\
\text { Before Incision }\end{array}$ & $\begin{array}{c}\text { SCIP } \\
\text { Compliance }\end{array}$ \\
\hline 1 & Hip Bipolar & Organ space & Ancef 1 gram & $<30$ minutes & Yes \\
\hline 2 & Colon Resection & Superficial & Ceftriaxone 2 grams & $<30$ minutes & Yes \\
\hline & & & & UTO Antibiotic given in Pre- & UTO \\
\hline 3 & Colon Resection & Superficial & 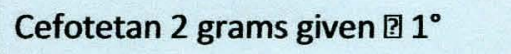 & op & \\
\hline 4 & Colon Resection & Organ space & Cefoxitin 2 grams $<1^{\circ}$ & $<1$ hour & Yes \\
\hline 5 & Colon Resection & Superficial & Cefoxitin 2 grams after start time & $<1$ hour & Yes \\
\hline 6 & Colon Resection & Superficial & Mefoxin 2 grams $<1^{\circ}$ & $<30$ minutes & Yes \\
\hline 7 & Colon Resection & Superficial & Cefoxitan 1 gram $<1^{\circ}$ & $<30$ minutes & Yes \\
\hline 8 & Colon Resection & Organ space & Cefoxitan 2 grams & $<30$ minutes & Yes \\
\hline
\end{tabular}


Table 5 illustrates the sample participants who were identified as having a SSI.

Overall, this table demonstrates that the selection of antibiotic for those procedures resulting in a SSI did meet the SCIP recommendations. The timing of the antibiotic in those cases where the administration of the antibiotic is less than 30 minutes prior to incision does meet SCIP recommendations, however this is not considered optimal timing for adequate tissue perfusion. During this time period, there were eight documented SSIs, three involving an organ space and five that were superficial.

Table 5

Surgical Site Infections October 1, 2010-March 31, 2011

\begin{tabular}{|c|c|c|c|c|c|}
\hline & Procedure & $\begin{array}{l}\text { Infection } \\
\text { Type } \\
\end{array}$ & Prophylactic Antibiotic & $\begin{array}{c}\text { Administration of Antibiotics } \\
\text { Before Incision }\end{array}$ & $\begin{array}{c}\text { SCIP } \\
\text { Compliance } \\
\end{array}$ \\
\hline 1 & Hip Bipolar & Organ space & Ancef 1 gram & $<30$ minutes & Yes \\
\hline 2 & Colon Resection & Superficial & Ceftriaxone 2 grams & $<30$ minutes & Yes \\
\hline 3 & Colon Resection & Superficial & Cefotetan 2 grams given $1^{\circ}$ & $\begin{array}{l}\text { UTO Antibiotic given in Pre- } \\
\text { op }\end{array}$ & UTO \\
\hline 4 & Colon Resection & Organ space & Cefoxitin 2 grams $<1^{\circ}$ & $<1$ hour & Yes \\
\hline 5 & Colon Resection & Superficial & Cefoxitin 2 grams after start time & $<1$ hour & Yes \\
\hline 6 & Colon Resection & Superficial & Mefoxin 2 grams $<1^{\circ}$ & $<30$ minutes & Yes \\
\hline 7 & Colon Resection & Superficial & Cefoxitan 1 gram $<1^{\circ}$ & $<30$ minutes & Yes \\
\hline 8 & Colon Resection & Organ space & Cefoxitan 2 grams & $<30$ minutes & Yes \\
\hline
\end{tabular}




\section{Summary and Conclusions}

In summary, this study evaluated the timely administration, appropriate selection, and dosage of preoperative prophylactic antibiotic in surgical patients. A retrospective research design was used to obtain data from 100 randomly selected colon, hysterectomy, total hip and total knee arthroplasty cases. These cases were then evaluated for the presence of a SSI. In more than half of the colon and hysterectomy cases, it was found that the prophylactic antibiotic was administered less than 30 minutes before surgical incision, and in more than half of the total hip and total knee arthroplasty cases, the antibiotic was administered in the 30-60 minute timeframe. The timeframe allows for adequate tissue perfusion as recommended in much of the literature. All the procedures met the SCIP recommendations for timing and selection of prophylactic antibiotic; however the evidence does support that adherence to the SCIP guidelines is necessary to reduce the risk of a SSI. The incidence of infection while relatively small does support the need for further investigation with regard to the timing of the prophylactic antibiotic and the need for prevention of further SSIs.

There were some limitations encountered while conducting this study. This researcher experienced difficulty locating specific subject data due to a hybrid charting system within the community hospital. The anesthesia record is completely on paper while the nursing documentation is all electronic. There was a portion of study data that had to be excluded due to incomplete documentation of the timing, selection, and dosage of prophylactic antibiotic. Secondly, the QI and IPC departments do not have software programs that communicate relevant data with regards to SCIP measures and patient 
infections. Both operating systems function independently, making correlation of data very time consuming. Lastly, the IPC department tracks those surgical infections reported by the surgeons or when a surgical patient is readmitted to the hospital. The accuracy with which a SSI is reported cannot always be determined and in most situations is based solely on notification from the surgeon.

Based on the findings of this study, it can be concluded that these practices were consistent with the guidelines. The timing of the preoperative prophylactic antibiotic did meet the SCIP guidelines of administration within one hour before surgical incision. However, the evidence clearly supports administration of the antibiotic within the optimal timeframe of between 30-60 minutes for adequate tissue perfusion and for prevention of a SSI. In all cases of a SSI, the selection of antibiotic were ones identified from the SCIP recommended list of antibiotics. The re-dosing of the antibiotic for procedures lasting greater than four hours did not occur in all the surgical cases, and weight adjusted dosing did not occur despite the significant number of patients identified as obese. Improvements can be made with regards to the timing and administration of preoperative prophylactic antibiotic. A recommendation will be made to the community hospital's Anesthesia and Surgical Department proposing that the prophylactic antibiotic be hung via IV in the preoperative holding unit and immediately prior to transfer to the operating room the antibiotic would be started. This would ensure that the preoperative prophylactic antibiotic is given within the 30-60 minute timeframe, thus reducing the potential for the development of a SSI and improving patient outcomes. 


\section{Recommendations and Implications}

One of the primary roles of the Advanced Practice Registered Nurse (APRN) is to improve the quality of patient care. This researcher identified a quality improvement opportunity that had the potential to improve patient safety and outcomes and enhance the clinical competence of the surgical team. Assuming the role of the APRN, this researcher proposes to develop a protocol for daily patient rounding on surgical units for the purpose of monitoring adherence to SCIP measures. Further education is needed for surgeons and perioperative staff regarding the common causes of SSIs and preventive measures that must be taken to prevent a SSI. Patients and their families should receive education prior to surgery regarding the definition of SSIs and what the patient can do to prevent an incidence. APRN leadership in furthering collaboration with the Anesthesia Department is needed to develop a protocol for initiating the prophylactic antibiotic in the pre-operative unit. This protocol would ensure that the timing of the antibiotic is within an optimal timeframe and that adequate tissue perfusion would occur.

In the study facility, it was primarily the Department of Anesthesia that administered the preoperative prophylactic antibiotics. The evidence supporting the administration of the prophylactic antibiotic within a 30-60 minute timeframe, as well as the results of this study, will be shared with the Anesthesia Department, Surgical Services Department, IPC and QI Departments. Recommendations for change will be discussed and extensive education and training must be provided to staff in all departments of Surgical Services to make this initiative successful. This quality practice change has the potential to improve 
patient outcomes by reducing the risk of developing a SSI and thus reduce any costs incurred to the hospital for the treatment of a SSI.

The APRN is instrumental in identifying further questions for clinical research. This study demonstrates the need for further research with regards to weight-adjusted dosing of prophylactic antibiotic for the bariatric patient population. On-going monitoring for implementation of best evidence-based interventions and evaluation of patient outcomes are key activities of the CNS.

Challenges in detecting and preventing SSIs continue to be problematic for healthcare facilities. Several organizations both national and international have collaborated to develop guidelines for the prevention of a SSI and other types of HAI. For example, The World Health Organization (WHO) developed a publication entitled Prevention of hospital-acquired infections: A practical guide (2002) which discussed HAI, the etiology, as well as prevention strategies. The $\mathrm{CDC}$ has developed the National Healthcare Safety Network (NHSN), an Internet based surveillance system which facilities can use to monitor the rates of SSI as well as to submit data related to HAIs as mandated by their specific state legislation (www.cdc.gov). TJC has included SSIs as a National Patient Safety Goal (NPSG - Goal 7_07 .05.001) and expects that healthcare facilities will perform targeted surveillance for SSIs for those procedures considered to be high risk for SSI. TJC also created the Surgical Site Infection Project with the aim of reducing SSIs in patients with colorectal surgery and procedures. The project is a collaboration that includes the American College of Surgeons (ACS), and it is utilizing the National Quality Improvement Program (NSQIP) for surgical outcome data collection and analysis. This 
effort is being undertaken to determine specific risk points and contributing factors related to SSIs and the aim is to then develop and implement solutions for the prevention of SSIs. The Society for Healthcare Epidemiology of America (SHEA) and Infectious Diseases Society of America (IDSA) have published the Compendium of Strategies to Prevent Healthcare-Associated Infections in Acute Care Hospitals (www.thejointcommisssion.org) that includes evidence-based practice information for acute care hospitals for the prevention HAIs. This document is a culmination of recommendations by those organizations that are considered champions in infection prevention: SHEA;IDSA; American Hospital Association (AHA); APIC; and TJC. The Institute For Healthcare Improvement (IHI), a not-for-profit organization that is instrumental in leading healthcare improvement, has issued a publication entitled: How-to Guide: Prevent Surgical Site Infections which identifies four components of care that are recommended by the IHI for the prevention of SSIs. The goal of all of these organizations is prevention of SSIs and to increase overall patient safety and healthcare quality. US health care policy must continue to emphasize, support, and promote healthcare quality.

Any improvement process related to the prevention of SSIs must be driven by the leadership within the healthcare organization. Involvement of a multidisciplinary team is essential in a SSI improvement project. This team should meet regularly to examine performance on antibiotic administration as well as the other SCIP measures, review pertinent hospital data, implement changes for improvement, and review the results. Process and system changes need to occur within the healthcare organization to improve 
administration of prophylactic antibiotics. The development and use of both electronic and paper standing orders that include the specifics related to the antibiotic timing, dose, and discontinuance is necessary for compliance The possible development of a pharmacist and/or nurse driven protocol that would include the type of antibiotic selection and dose and all based on SCIP guidelines should be considered. The responsibility for the dosing of the antibiotic should be assigned to either anesthesia or a designated nurse to improve the timeliness. A visible reminder or checklist to remind staff to give an antibiotic could be developed and implemented in the preoperative areas. The involvement of pharmacy, infection control and nursing should occur to ensure that the prophylactic antibiotics are selected and given in a timely manner. The CNS is trained and well prepared to assume a leadership role within the inter-disciplinary team to assure that high quality care remains an institutional priority. 


\section{Appendix A CMS Core Measure SCIP: Surgical Care Improvement Project}

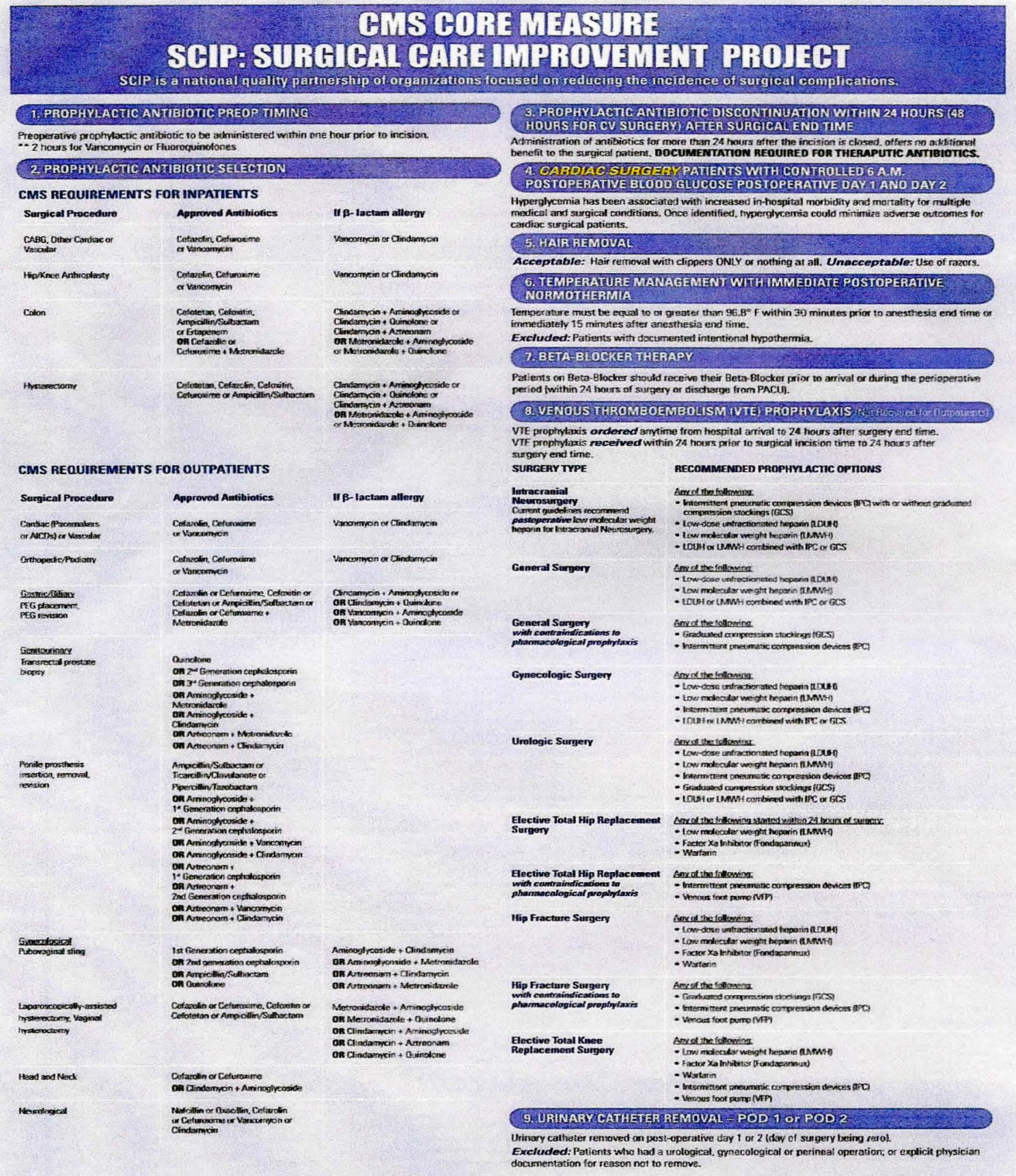


Appendix B Prophylactic Antibiotic Regimen Selection for Surgery

$S C I P-\operatorname{Inf}-2-5$

Specifications Manual for National Hospital Inpatient Quality Measures 04-01-2011-12-31-2011

\begin{tabular}{|l|l|}
\hline Surgical Procedure & Approved Antibiotics \\
\hline CABG,other Cardiac or & $\begin{array}{l}\text { Cefazolin,Cefuroxime,or Vancomycin. If } \beta \text {-lactam } \\
\text { allergy:Vancomycin or Clindamycin }\end{array}$ \\
\hline Hip/Knee Arthroplasty & $\begin{array}{l}\text { Cefazolin,Cefuroxime,or Vancomycin. If } \beta \text {-lactam } \\
\text { allergy:Vancomycin or Clindamycin } \\
\text { Cefotetan,Cefoxitin,Ampicillin/Sulbactam or Ertapenem OR } \\
\text { Cefazolin,or Cefuroxime+Metronidazole.IF } \beta \text {-lactam } \\
\text { allergy:Clindamycin+Aminoglycoside or } \\
\text { Clindamycin=Quinolone or Clindamycin+Aztreonam OR } \\
\text { Metronidazole with Aminoglycoside or Metronidazole } \\
+ \text { Quinolone }\end{array}$ \\
\hline Hysterectomy & $\begin{array}{l}\text { Cefetetan,Cefazolin,Cefoxitin,Cefuroxime or } \\
\text { Ampicillin/Sulbactam.If } \beta \text {-lactam allergy: } \\
\text { Clindamycin+Aminoglycoside, Clindamycin=Quinolone, } \\
\text { Clindamycin+Aztreonam } 0 \text { OR Metronidazole with } \\
\text { Aminoglycoside or Metronidazole }+ \text { Quinolone }\end{array}$ \\
\hline
\end{tabular}


Appendix C Perioperative Patient Focused Model

\section{Perioperative Patient Focused Model $\odot$}

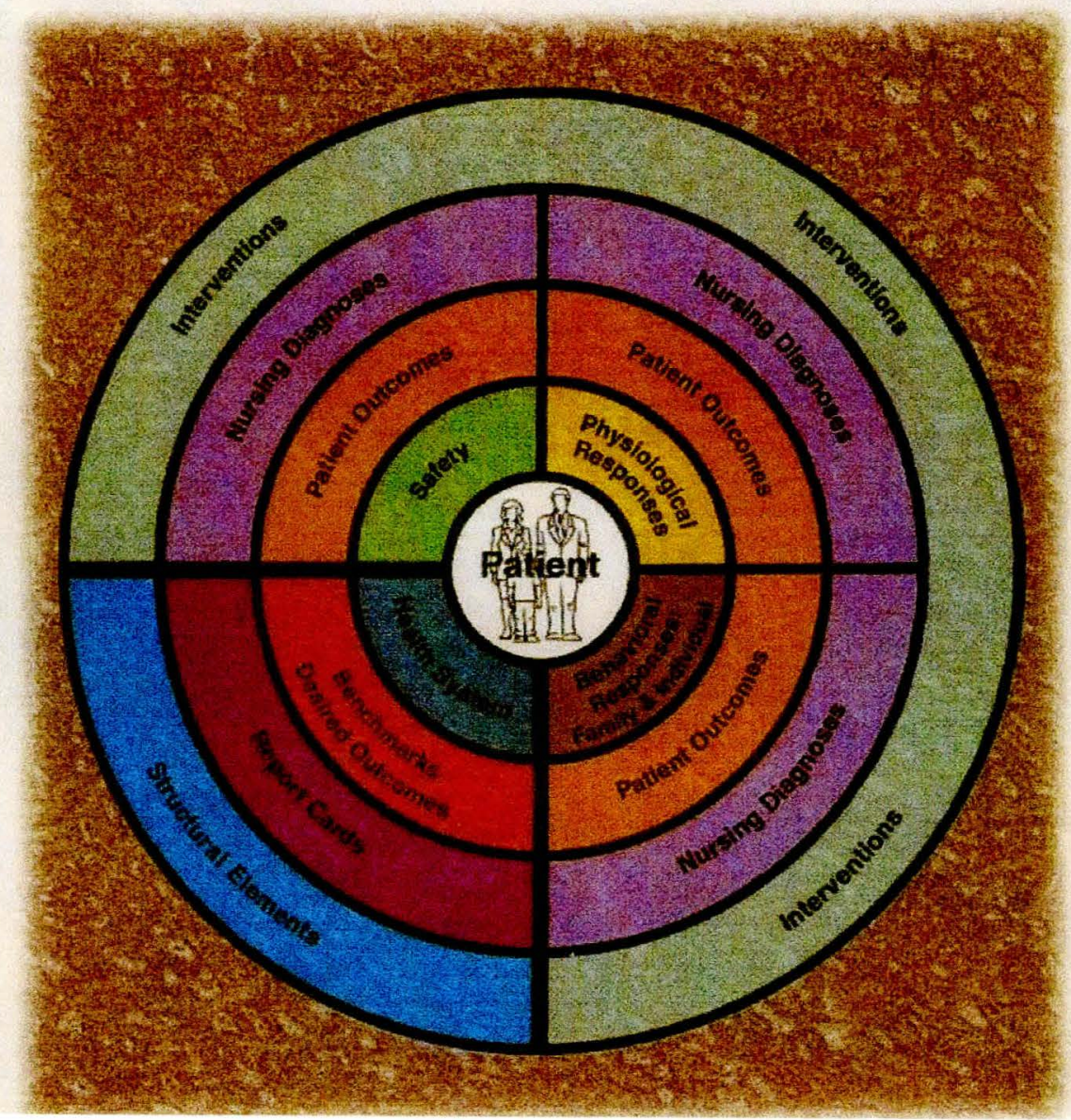


Appendix D Data Collection Tool

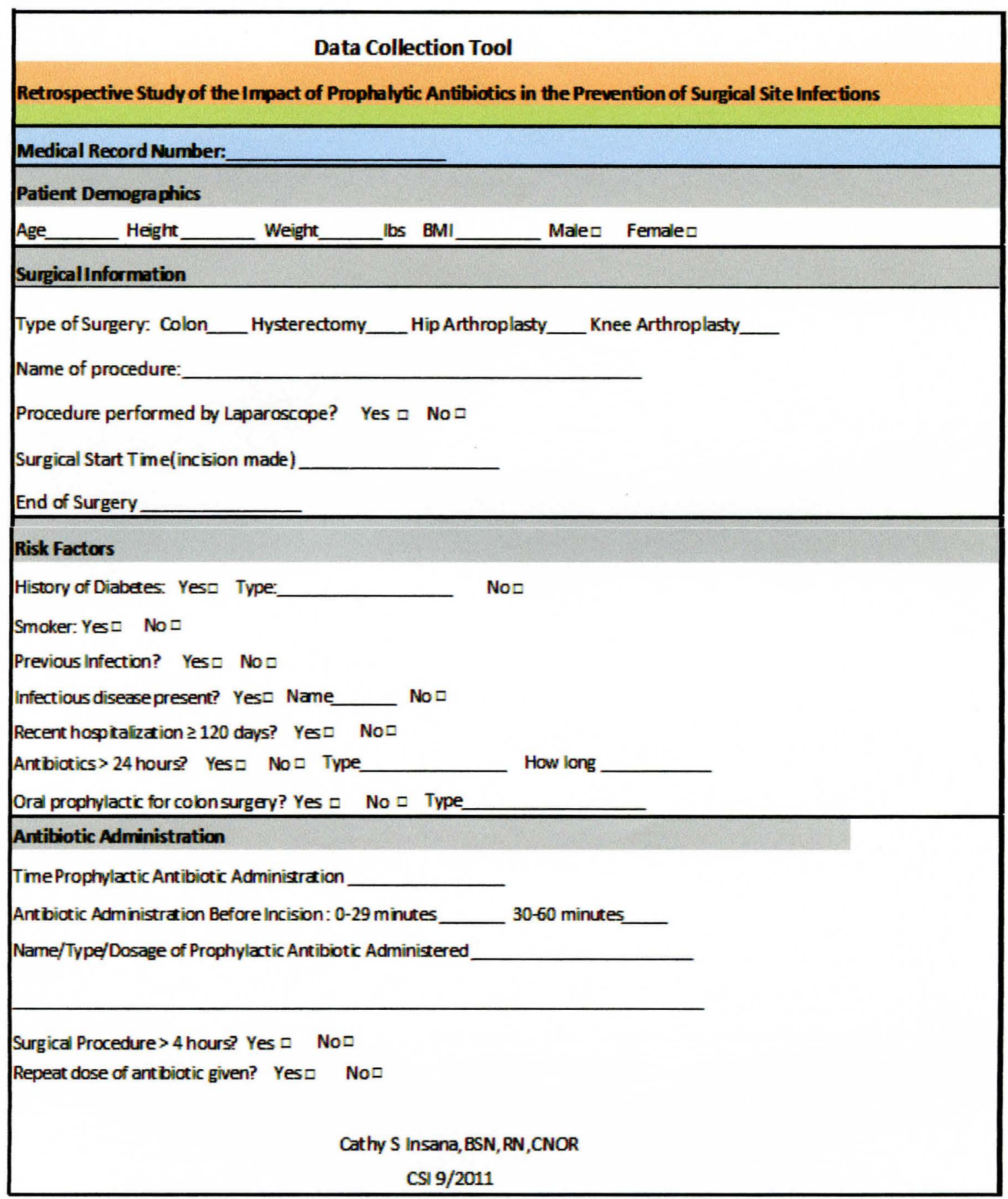




\section{References}

Anderson, D. J., Harris, A., \& Sexton, D. J. (2011). Overview of control measures to prevent surgical site infection. In E. L. Baron (Ed.), UpToDate. Retrieved from http://www.uptodate.com/contents/overview-of-control-measures-to-preventsurgical-site-infections

Anderson D. J., Harris, A., \& Sexton, D. J. (2011). Overview of control measures to prevent surgical site infections. Retrieved from http://www.uptodate.com/contents/overview-of-control-measures-to-preventsurgical-site-infections.html.

Anderson, D. J., Kaye, K. S., Classen, D., Arias, K. M., Podgorny, K., Burstin, H., \& Yokoe, D. S. (2008). Strategies to prevent surgical site infections in acute care hospital [SHEA/IDSA Practice Recommendations]. Infection Control and Hospital Epidemiology, 29(1), S51-S61.

Barnett, T. E. (2007). The not so hidden costs of surgical site infections. AORN Journal, 86(2), 249-258.

Bratzler, D. W., \& Hunt, D. R. (2006). The surgical infection prevention and surgical care improvement projects: National initiatives to improve outcomes for patient having surgery [Invited Article: Healthcare Epidemiology]. Clinical Infectious Diseases, 43, 322-330.

Bucher, B. T., Warner, B. W., \& Dillon, P. A. (2011, June). Antibiotic Prophylaxis and the Prevention of Surgical Site Infection. Current Opinion in Pediatrics, 23(3), 334-338. 
Centers for Disease Control and Prevention (2012,May). National Healthcare Safety Network. Retrieved from http://www.cdc.gov/nhsn/index.html.

Clancy, C. M. (2008). SCIP: Making complications of surgery the exception rather than the rule. AORN Journal, 87(3), 621-624.

Classen, D. C., Evans, R. S., Pestotnik, S. L., Horn, S. D., Menlove, R. L., \& Burke, J. P. (1992). The Timing of Prophylactic Administration of Antibiotics and the Risk of Surgical-Wound Infection. New England Journal of Medicine, 326(5), 281-286.

Edmiston, C. E., Kelly, H., Larson, J., Andris, D., \& Hennen, D. (2004). Perioperative antimicrobial prophylaxis in the gastric bypass patient: Do we achieve therapeutic levels? Surgery 2004, 136, 738-747.

Fry, D. E., \& Fry, R. V. (2007). Surgical site infections: The host factor. AORN Journal, $86,801-814$.

Fuller, R. L., McCullough, E. C., Bao, M. Z., \& Averill, R. F. (2009). Estimating the costs of potentially preventable hospital acquired complications. Heath Care Financing Review, 30(4), 17-30.

Institute For Healthcare Improvement.(2012) How-to guide: prevent surgical site infections. Retrieved from www.ihi.org.

Kirkland, K. B., Briggs, J. P., Trivette, S. L., Wilkinson, W. E., \& Sexton, D. J. (1999). The impact of surgical-site infections in the 1990s: attributable mortality, excess length of hospitalization, and extra costs. Infection Control Hospital Epidemiology, 20, 725-730. 
Meeks, D. W., Lally, K. P., Carrick, M. M., Lew, D. F., Thomas, E. J., Doyle, P. D., \& Kao, L. S. (2011). Compliance with guidelines to prevent surgical site infections: As simple as 1-2-3? The American Journal of Surgery, 201, 76-83.

Nelson, R. L., Glenny, A. M., \& Song, F. (2008, October 9). Antimicrobial prophylaxis for colorectal surgery [Intervention Review The Cochrane Collaboration]. John Wiley \& Sons, Ltd.

Owens, C. D., \& Stoessel, K. (2008). Surgical site infections: epidemiology, microbiology, and prevention [Science Direct]. The Journal of Hospital Infection, $70(2), 3-10$.

Polit, D. F., \& Beck, C. T. (2008). Nursing research: generating and assessing evidence for nursing practice. ( ed.). Philadelphia, PA: Lippincott Williams \& Wilkins.

Rothrock, J., \& Smith, D. (2000). Selecting the perioperative patient focused model. AORN Journal, 71(5)(5), 1030-1037.

Rothrock,J., \& Smith, D. (2000).Selecting the perioperative patient focused model. AORN Journal, 71(5), 1030-1037.

Steinburg, J. P., Braun, B. I., Hellinger, W. C., Kusek, L., Bozikis, M. R., Bush, A. J., \& Kritchevsky, S. B. (2009). Timing of antimicrobial prophylaxis and the risk of surgical site infections: Results from the trial to reduce antimicrobial prophylaxis errors. Annals of Surgery, 250(1), 10-16. 
The Joint Commission. (2010, August). Facts about the surgical site infection project. Retrieved from http://www.centerfortransforminghealthcare.org/assets/4/6/CTH_SSI_Fact_Sheet. pdf

The Joint Commission. (2011, August). Compendium of strategies to prevent healthcareassociated infection in acute care hospitals. Retrieved from http://www.jointcommission.org/topics/hai_ssi.aspx.

The World Health Organization. (2002). Prevention of hospital-acquired infections: a practical guide. Retrieved from http://www.who.int/csr/resources/publications/drugresist/en/whocdscsreph20021 2.pdf

Wanzer, L., Goeckner, B., \& Hicks, R. W. (2011, March). Perioperative Pharmacology: Antibiotic Administration. AORN Journal, 93(3), 340-351.

Weber, W. P., Marti, W. R., Zwahlen, M., Rosenthal, H., Fueglistaler, P., Reck, S., \& Widmer, A. F. (2008). The timing of surgical antimicrobial prophylaxis. Annuals of Surgery, 247(6), 918-926.

Zaidi, N., Tariq, M., \& Breslin, D. (2009). Preoperative use of antibiotics in elective surgical patients: Timing of administration [Research \& Audit]. Journal of Perioperative Practice, 19(7), 225-227.

Zanetti, G., Giardina, R., \& Platt, R. (2001, September-October). Intraoperative redosing of cefazolin and risk for surgical site infection in cardiac surgery. Emergency Infectious Disease, 7(5), 828-821. 